\title{
Effect of nifedipine on enzymatically estimated infarct size in the early phase of acute myocardial infarction
}

\author{
L J E WALKER, G MACKENZIE, A A J ADGEY \\ From the Regional Medical Cardiology Centre and Department of Community Medicine, Royal Victoria \\ Hospital, and Queen's University, Belfast
}

SUMMARY In a double blind placebo controlled trial, 434 patients with suspected myocardial infarction were randomised to treatment with nifedipine $(n=217)$ or placebo $(n=217)$ within six hours from the onset of chest pain. During the treatment period of 48 hours, a $10 \mathrm{mg}$ capsule containing nifedipine or placebo was given sublingually every four hours for 24 hours, then orally every four hours for the next 24 hours. Acute myocardial infarction was confirmed in 295 patients (146 in the nifedipine group and 149 in the placebo group). The median delay time to intervention with nifedipine in patients with acute myocardial infarction was 111 minutes. Infarct size was assessed by the estimation of release of creatine kinase isoenzyme $\mathrm{MB}$ and creatine kinase from blood samples taken every four hours for 48 hours. The total mean (SEM) creatine kinase MB released was $406 \cdot 4(27 \cdot 2) \mathrm{IU} / 1$ in the nifedipine group and $345 \cdot 7(20.5) \mathrm{IU} / 1$ in the placebo group. Total mean (SEM) creatine kinase released was $2749.6(165 \cdot 1)$ IU/1 in the nifedipine group and 2698.4 (145.9) IU/1 in the placebo group. In hospital mortality was similar for both the nifedipine and placebo groups (6.6\% and $5.8 \%$ respectively). Treatment with nifedipine in the early phase of acute myocardial infarction seems to have no effect on enzymatically measured infarct size.

Experiments in dogs suggest that nifedipine, a calcium channel blocking agent, can reduce the area of myocardial necrosis after coronary artery occlusion. ${ }^{1-6}$ Nifedipine can reduce cardiac work, and therefore myocardial oxygen demand, by decreasing peripheral vascular resistance as a result of its strong peripheral vasodilatory effect. It can also increase coronary blood flow by coronary artery vasodilatation and improve collateral blood flow. ${ }^{134}$ At a cellular level, nifedipine has been shown to reduce intramitochondrial calcium overload. ${ }^{4}$

The success of nifedipine as a means of reducing infarct size in dogs has not been reproduced in clinical studies. This is perhaps surprising, in view of the apparently beneficial haemodynamic effects of nifedipine in the early phase of acute myocardial infarction in man. ${ }^{7}$ Two randomised, double blind, placebo controlled studies have failed to show

Requests for reprints to: Dr A A J Adgey, Regional Medical Cardiology Centre, Royal Victoria Hospital, Belfast BT12 6BA.

Accepted for publication 22 October 1987 evidence of reduction of myocardial infarct size ${ }^{89}$ after the administration of nifedipine in patients with acute myocardial infarction. These two groups hypothesised that the relatively long delay to intervention with nifedipine in their studies $(4 \cdot 6(0 \cdot 1)$ hour (mean (SEM)) in the study by Muller et $a l^{8}, 5 \cdot 5$ (2.9) hour (mean (SD)) in the study by Sirnes et al $^{9}$ ) may have accounted for the failure of nifedipine to limit infarct size. A randomised double blind study of patients seen within 24 hours of the onset of symptoms of acute myocardial infarction showed no reduction in one month mortality in those who were treated actively with nifedipine compared with the placebo group. ${ }^{10} \mathrm{We}$ planned to minimise the delay to intervention with nifedipine by starting treatment when patients were first seen by the staff of the mobile coronary care unit.

\section{Patients and methods}

All patients admitted with suspected myocardial infarction to the Regional Medical Cardiology Centre, Royal Victoria Hospital between December 1984 
and February 1986 were considered for entry to the study, which was double blind, randomised, and placebo controlled. Verbal consent was obtained initially. The variability of infarct size as measured by total release of creatine kinase $\mathrm{MB}$ isoenzyme was assessed from 55 patients who entered a pilot study. From this it was estimated that 200 patients with definite myocardial infarction were needed in the double blind study to detect a $20 \%$ reduction in infarct size. Definite myocardial infarction was defined as an increase in peak creatine kinase $M B$ to $>30 \mathrm{IU} / 1$ (more than twice the upper limit of normal) in a patient with central chest pain for $\geqslant 30$ minutes that appeared to be cardiac in origin regardless of electrocardiographic changes.

We excluded patients seen $\geqslant 6$ hours after the onset of pain, those aged $>75$ years, and those with systolic blood pressure of $\leqslant 85 \mathrm{~mm} \mathrm{Hg}$.

When patients were first seen an intravenous cannula was inserted and intravenous analgesia was given if required. When the patients' condition was stable their eligibility for entry to the study was considered. Patients were randomly allocated to treatment with nifedipine or placebo by the attending doctor, who selected the next container available from a series of sequentially numbered containers provided by the pharmacy department and labelled as dictated by a randomisation schedule supplied by the statistician. Each container held sufficient capsules of either nifedipine or placebo to last the 48 hour period of treatment. Access to information on which container contained nifedipine or placebo was restricted to the hospital pharmacist and the data processing supervisor. After the patient was discharged from hospital the supervisor broke the code to record the allocation to treatment with nifedipine or placebo on the questionnaire that recorded data on each patient.

The initial sublingual dose of $10 \mathrm{mg}$ nifedipine or placebo was repeated every four hours for 24 hours, and then an oral dose was given every four hours for the next 24 hours. When the patient was first seen 10 $\mathrm{ml}$ of venous blood was taken. Further samples were taken from a heparinised intravenous cannula every four hours throughout the $\mathbf{4 8}$ hour study period for later estimation of creatine kinase $M B$, creatine kinase, aspartate transaminase, and myoglobin.

All samples were centrifuged within 24 hours of being drawn and the sera were pipetted off and stored at $4^{\circ} \mathrm{C}$. Subsequently these samples were analysed in batches. Creatine kinase and aspartate transaminase were assayed on a multichannel analyser. We used the CK-MB (NAC-act) UV-system kit (Boehringer Mannheim Diagnostica). All enzymes were assayed at $37^{\circ} \mathrm{C}$. We used the Myoglobin RIA kit of NMS Pharmaceuticals for the radioimmunoassay of serum myoglobin.
Several hours after entry to the study, when the
I were asked whether they wished to remain in the study. Pulse and blood pressure were recorded every $\frac{\rho}{?}$ half hour for two hours, then the pulse was measured $\frac{}{6}$ hourly and blood pressure every four hours while the $\frac{\bar{F}}{\overline{0}}$. patient remained in the coronary care unit. Routine $\frac{\bar{\omega}}{\sigma}$ investigations (for example blood gases and elec- $\_$ trocardiograms) took place as usual in the coronary is care unit.

Intravenous streptokinase was given to 44 patients in this study (27 of whom were in the nifedipine $\vec{\omega}$ group and 17 in the placebo group). Criteria for the $\frac{\mathscr{D}}{S}$ administration of this drug were $(a)$ age $<70$, (b) ST segment elevation of $\geqslant 4 \mathrm{~mm}$ on the initial of electrocardiogram, (c) total delay time $<4$ hours, $\stackrel{+}{-}$ (d) no contraindications to anticoagulant treatment. $\vec{c}$ In patients with successful recanalisation after streptokinase treatment, creatine kinase concentration peaks earlier and these patients have a greater $\vec{\nabla}$ cumulative release of creatine kinase than conventionally treated patients with an infarct of similar size. ${ }^{11}$ For this reason patients who had received $\varnothing_{\infty}$

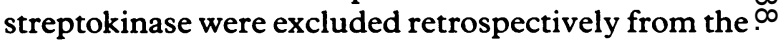
randomised controlled trial.

Patients were withdrawn from the study if $(a)$ two consecutive capsules had to be omitted because systolic blood pressure had fallen to $<85 \mathrm{~mm} \mathrm{Hg}$ or (b) if the patient refused to participate further, or $(c) \stackrel{\mathbb{Q}}{\stackrel{2}{ }}$ if side effects developed that seemed to be related to $\overrightarrow{\overrightarrow{0}}$ nifedipine treatment.

One of us completed a questionnaire on all entrants $\vec{P}$ to the study. This contained information on patients' baseline characteristics, cardiac enzyme results, need for additional drug treatment during the 48 hour study period, and major complications occurring during the hospital stay. The data were entered into a 3 . magnetic file on a PDP 11/34A computer by the staffo of the data processing department of the Department of Community Medicine, of Queen's University, 0 Belfast.

CALCULATION OF INFARCT SIZE Infarct size was calculated by a computer program incorporating Norris's adaptation of Sobel's formula N (that is integrated appearance function for creatine kinase $\left.=\mathrm{Et}+\mathrm{Kd} \sum \mathrm{Edt}\right){ }^{12}$ All estimates of total $\sigma$ creatine kinase and total creatine kinase MB released using this program were made by one of us. The peak values of creatine kinase, creatine kinase $\mathrm{MB}$, aspartate transaminase, and myoglobin and the time from 0 the onset of chest pain to peak values were also $\overline{+}$ recorded.

On completion of the study, statistical analyses $\frac{\vec{Q}}{\square}$ were carried out by SPSS-11 (Statistical Package for the Social Sciences) on a PDP 11/34A computer. Statistical tests used included $\chi^{2}$ test on discreteo 


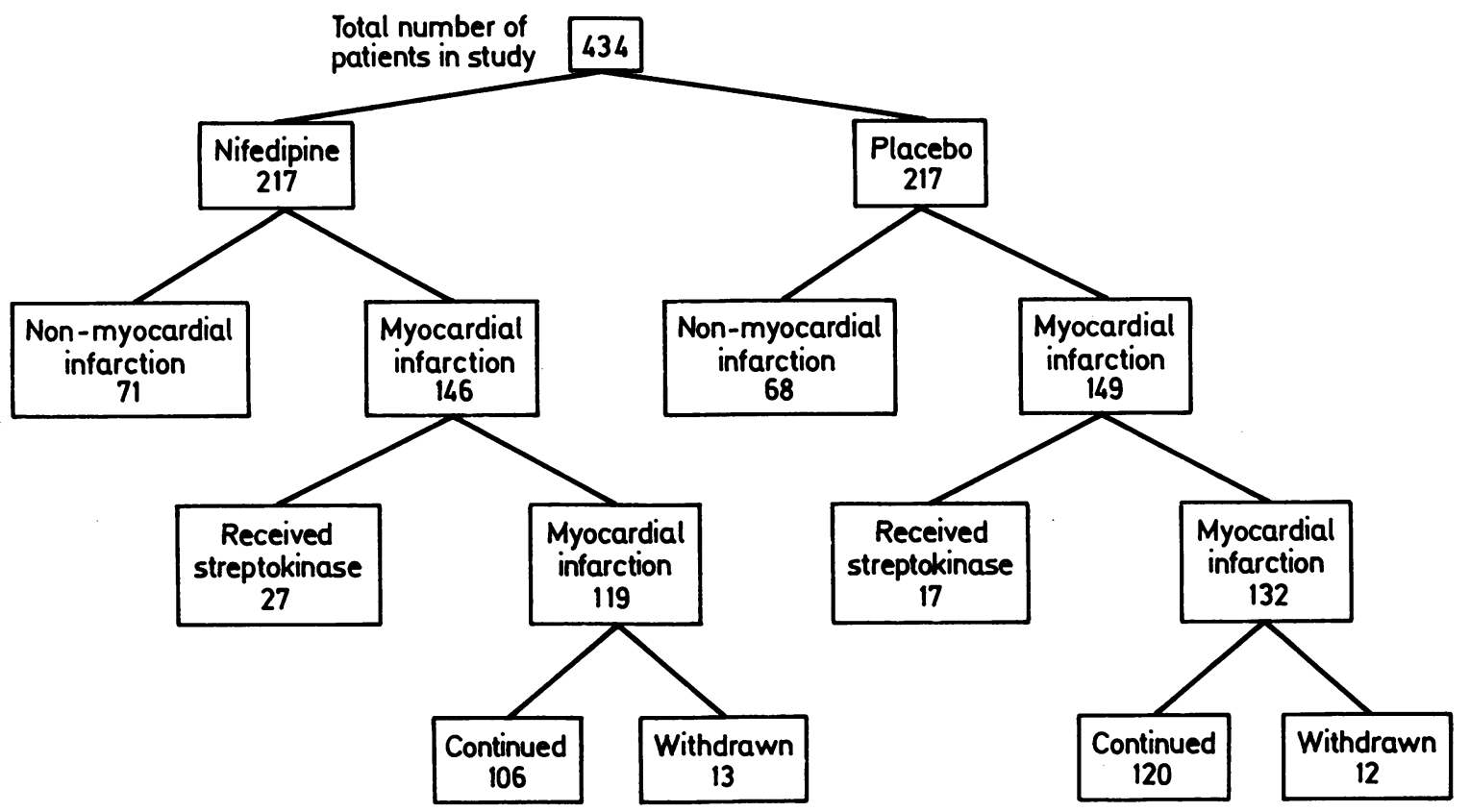

Fig 1 Distribution of patients between nifedipine and placebo treated groups.

variables and Student's $t$ test and one way analysis of variance on continuous variables. The $5 \%$ level of significance was used throughout the study. Multiple regression methods of analysis were also used.

\section{Results}

Four hundred and thirty four patients with suspected myocardial infarction entered the study. Two hundred and seventeen were randomised to treatment with nifedipine and 217 to placebo. Acute myocardial infarction was confirmed in 295 patients-146 in the treatment group and 149 in the placebo group. Of 44 patients with definite myocardial infarction who received thrombolytic treatment, 27 were in the treatment group and 17 were in the placebo group. This difference in the proportion of patients allocated to treatment or placebo was not statistically significant. A further 25 patients withdrew from the study (13 in the treatment and 12 in the placebo group) (fig 1). Reasons for withdrawal included: (a) patient refusal to participate further (eight in the nifedipine treated group and five in the placebo group); (b) development of hypotension (systolic blood pressure $<85 \mathrm{~mm} \mathrm{Hg}$ ) in five patients in the nifedipine treated group and six patients in the placebo group; (c) need for nifedipine treatment in one patient in the placebo group. Data from patients who received streptokinase or who were withdrawn from the study were excluded retrospectively from the analysis. Tables 1 and 2 summarise baseline characteristics of the remaining 226 patients with myocardial infarction who completed the study. Only three baseline characteristics were significantly different in the nifedipine and placebo groups. More patients (60: $106(56.6 \%))$ in the nifedipine group had a history of angina than those in the placebo group (50: $120(41.7 \%))(p<0.05)$. A significantly smaller proportion of patients in the nifedipine group were current smokers than in the placebo group $(34.9 \%$ versus $51.7 \%$ respectively) ( $p<0.05$ ). Patients in the nifedipine group were less likely to have needed atropine when they were first seen $(2.8 \%$ versus $9.2 \%)(p<0.05)$ (table 1$)$.

\section{CARDIAC ENZYME DATA}

Values for peak creatine kinase $\mathrm{MB}$, total creatine kinase $M B$ released (figs 2 and 3), peak creatine kinase, total creatine kinase released, peak aspartate transaminase, peak myoglobin, and the times to the peak activities of all the enzymes in patients in the nifedipine and placebo groups were compared by Student's $t$ test, as were the values of the individual dissociation constants $(\mathrm{Kd})$ used in the estimation of enzyme release. In all but 15 patients (eight in the nifedipine group and seven patients in the placebo group) the size of the infarct could be estimated from the total creatine kinase MB released. Results were 
Table 1 Baseline variables in the 226 patients with myocardial infarction randomised to nifedipine $(N)$ or placebo (P)

\begin{tabular}{|c|c|c|}
\hline Baseline variable & $\begin{array}{l}N(\%) \\
(n=106)\end{array}$ & $\begin{array}{l}P(\%) \\
(n=120)\end{array}$ \\
\hline Sex (male) & $87(82 \cdot 1)$ & $95(79 \cdot 2)$ \\
\hline \multicolumn{3}{|l|}{ Past history of: } \\
\hline Angina & $60(56 \cdot 6)$ & $\begin{array}{l}50(41 \cdot 7) \\
23(19 \cdot 2)\end{array}$ \\
\hline $\begin{array}{l}\text { Fypertension } \\
\text { Diabetes mellitus }\end{array}$ & $\begin{aligned} 31 & (29 \cdot 2) \\
3 & (2 \cdot 8)\end{aligned}$ & $\begin{array}{l}23(19 \cdot 2) \\
10(8 \cdot 3)\end{array}$ \\
\hline $\begin{array}{l}\text { Dyspnoea caused by coronary } \\
\text { disease }\end{array}$ & $1(0.9)$ & $3(2 \cdot 5)$ \\
\hline Previous myocardial infarction & $35(33 \cdot 0)$ & $37(30 \cdot 8)$ \\
\hline Current smoker & $37(34 \cdot 9)$ & $62(51 \cdot 7)$ \\
\hline \multicolumn{3}{|l|}{$\begin{array}{l}\text { Regular medication before entry to the } \\
\text { study: }\end{array}$} \\
\hline Nifedipine & $25(23 \cdot 6)$ & $23(19 \cdot 2)$ \\
\hline$\beta$ blocker & $26(24 \cdot 5)$ & $25(20 \cdot 8)$ \\
\hline Diuretic & $23(21 \cdot 7)$ & $23(19 \cdot 2)$ \\
\hline Long acting nitrate & $10(9 \cdot 4)$ & $16(13 \cdot 3)$ \\
\hline $\begin{array}{l}\text { Resuscitation from VF before entry to } \\
\text { study }\end{array}$ & $4(3.8)$ & $4(3 \cdot 3)$ \\
\hline \multicolumn{3}{|l|}{$\begin{array}{l}\text { Medication before being seen by ward } \\
\text { staff: }\end{array}$} \\
\hline Narcotic analgesia & $28(26 \cdot 4)$ & $21(17 \cdot 5)$ \\
\hline Sublingual glyceryl trinitrate & $27(25 \cdot 5)$ & $25(20 \cdot 8)$ \\
\hline \multicolumn{3}{|l|}{ Cardioactive drugs from ward staff: } \\
\hline $\begin{array}{l}\beta \text { blocker } \\
\text { Diuretic }\end{array}$ & $4(3 \cdot 8)$ & $5(4 \cdot 2)$ \\
\hline Atropine & $\begin{aligned} 14(13 \cdot 2) \\
3(2 \cdot 8)\end{aligned}$ & $16(13 \cdot 3)$ \\
\hline \multicolumn{3}{|l|}{ Electrocardiographic data: } \\
\hline Initial heart rhythm sinus & $105(99 \cdot 1)$ & $117(97 \cdot 5)$ \\
\hline ST segment elevation on the initial & & \\
\hline ECG & $62(58 \cdot 5)$ & $79(65 \cdot 8)$ \\
\hline \multicolumn{3}{|l|}{ Site of infarct: } \\
\hline Anterior & $43(40 \cdot 6)$ & $51(42 \cdot 5)$ \\
\hline Inferior & $38(35 \cdot 8)$ & $41(34 \cdot 2)$ \\
\hline Other & $25(23.5)$ & $28(23 \cdot 3)$ \\
\hline Type of infarct: & 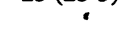 & \\
\hline Transmural & $69(65 \cdot 1)$ & $76(63 \cdot 3)$ \\
\hline Subendocardial & $14(13 \cdot 2)$ & $20(16 \cdot 7)$ \\
\hline Other & $23(21 \cdot 7)$ & $24(20 \cdot 0)$ \\
\hline $\begin{array}{l}\text { No conduction disturbance on the } \\
\text { initial ECG }\end{array}$ & $101(95 \cdot 3)$ & $115(95 \cdot 8)$ \\
\hline \multicolumn{3}{|l|}{ Initial chest $x$ ray: } \\
\hline Normal & $70(66 \cdot 0)$ & $78(65 \cdot 0)$ \\
\hline Pulmonary vascular congestion & $28(26 \cdot 4)$ & $34(28 \cdot 3)$ \\
\hline Pulmonary oedema & $8(7 \cdot 5)$ & $8(6 \cdot 7)$ \\
\hline
\end{tabular}

ECG, electrocardiogram; VF, ventricular fibrillation.

not available in these patients, eithèr because a series of blood samples was incomplete or because fluctuation of enzyme activity made enzymatic estimation of infarct size impossible. In two patients in the treatment group and one patient in the placebo group, peak creatine kinase $M B$ could be identified even though estimation of total creatine kinase $\mathrm{MB}$ released was not feasible.

Total creatine kinase MB released was 406.43 $(27 \cdot 22) \mathrm{IU} / \mathrm{l}$ (mean (SEM)) in patients in the treatment group ( $\mathrm{n}=98)$ and $345.75(20.48) \mathrm{IU} / 1$ in patients in the placebo group $(n=113)$ (table 3 ). This difference was not statistically significant. The range of total creatine kinase $\mathrm{MB}$ released was 51$1470 \mathrm{IU} / 1$ in the treatment group and 37-1199 IU/1 in the placebo group (table 3 , fig 2 ). Peak creatine kinase
Table 2 Comparison of the means (SEM) of the continuous variables in the 226 patients with myocardial infarction

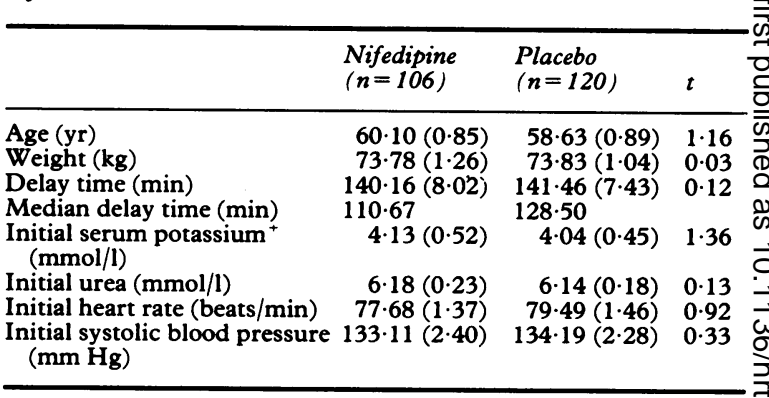

MB was not significantly different in the treatment group $(\mathrm{n}=100)$ and in the placebo group $(\mathrm{n}=114)$ (211.91 (12.77) and 189.38 (9.73) IU/1 respectively). The range of values for peak creatine kinase $\mathrm{MB}$ was 45-613 IU/1 in the treatment group and 36-526 IU/1 in the placebo group (fig 3).

Multiple regression analysis showed no evidence of a relation between the three baseline factors known to differ between treatment and placebo groups and in peak creatine kinase $\mathrm{MB}$ or total creatine kinase MB released.

Estimates of infarct size from creatine kinase were available in fewer patients than estimates from the creatine kinase $M B$ isoenzyme, primarily because creatine kinase activity had sometimes not returned to baseline values by the end of our 48 hour sampling period. This was the case in $10(9.4 \%)$ patients in the treatment group and seven $(5.8 \%)$ patients in the placebo group. In addition, we excluded results from patients in whom cardioversion was performed or in whom cardiogenic shock had developed or who received intramuscular injections, because these factors are known to interfere with creatine kinase activity. Total creatine kinase released was $2749 \cdot 64$ $(165 \cdot 14) \mathrm{IU} / \mathrm{l}$ in the treatment group $(\mathrm{n}=77)$, and $2698.39(145.86) \mathrm{IU} / 1$ in the placebo group $(n=89)$ (table 4). The range of total creatine kinase released was 591-9623 IU/1 in the treatment group and 483$7154 \mathrm{IU} / 1$ in the placebo group (table 4). Peak OI creatine kinase was $1938.24(156.63) \mathrm{IU} / \mathrm{l}$ in the $\tilde{O}$ treatment group $(n=87)$, and $1839.58(118 \cdot 64) \mathrm{IU} / 1$ N

Table 3 Total creatine kinase $M B(I U / l)$ released by nifedipine and placebo treated groups

\begin{tabular}{|c|c|c|}
\hline & $\begin{array}{l}\text { Nifedipine } \\
(n=98) \\
(\text { Mean } \\
(\text { SEM) })\end{array}$ & $\begin{array}{l}\text { Placebo } \\
(n=113) \\
(\text { Mean } \\
(\text { SEM) }\end{array}$ \\
\hline $\begin{array}{l}\text { Total creatine kinase } \mathrm{MB} \text { released } \\
\text { Range of total creatine kinase } \mathrm{MB}\end{array}$ & $\begin{array}{l}406 \cdot 43(27 \cdot 22) \\
51-1470\end{array}$ & $\begin{array}{l}345 \cdot 75(20 \cdot 48) \\
37-1199\end{array}$ \\
\hline
\end{tabular}




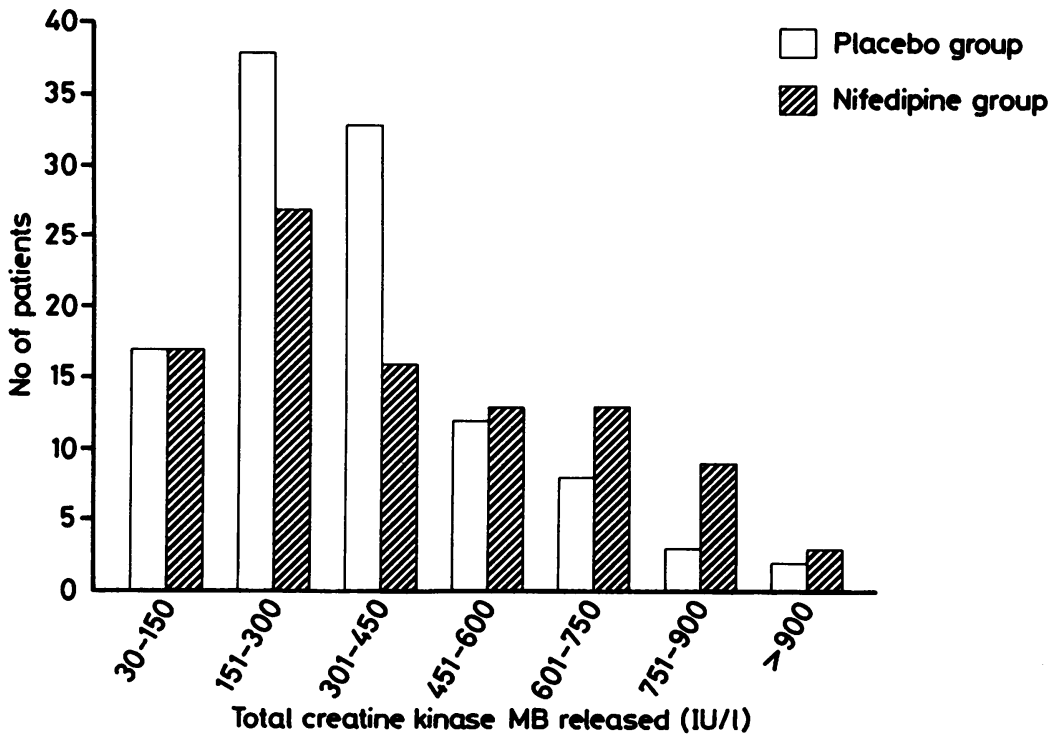

Fig 2 Total creatine kinase $M B$ released by patients with myocardial infarction, 98 of whom were treated with nifedipine and 113 of whom were treated with placebo.

in the placebo group $(n=96)$. The range of peak creatine kinase values was $423-9748$ IU $/ 1$ in the treatment group and 409-7923 IU/1 in the placebo group. None of these differences was statistically significant.

The time from the onset of pain to the peak creatine kinase $\mathrm{MB}$ was $18.20(0.54)$ hours in the treatment group and $17.98(0.58)$ hours in the placebo group. The time from the onset of pain to peak creatine kinase activity was $21.67(0.70)$ hours in the treatment group and $21.34(0.66)$ hours in the placebo group. Neither of these differences was statistically significant.

\section{Kd VALUES}

The mean (SEM) value of Kd used to estimate infarct size from creatine kinase $\mathrm{MB}$ in patients in the nifedipine group was $10772(379)\left(10^{-7}\right)$ and 10252 (308) $\left(10^{-7}\right)$ in the placebo group. The mean (SEM) value of $\mathrm{Kd}$ used to estimate infarct size from creatine kinase in patients in the nifedipine group was $\mathbf{7 5 3 6}$

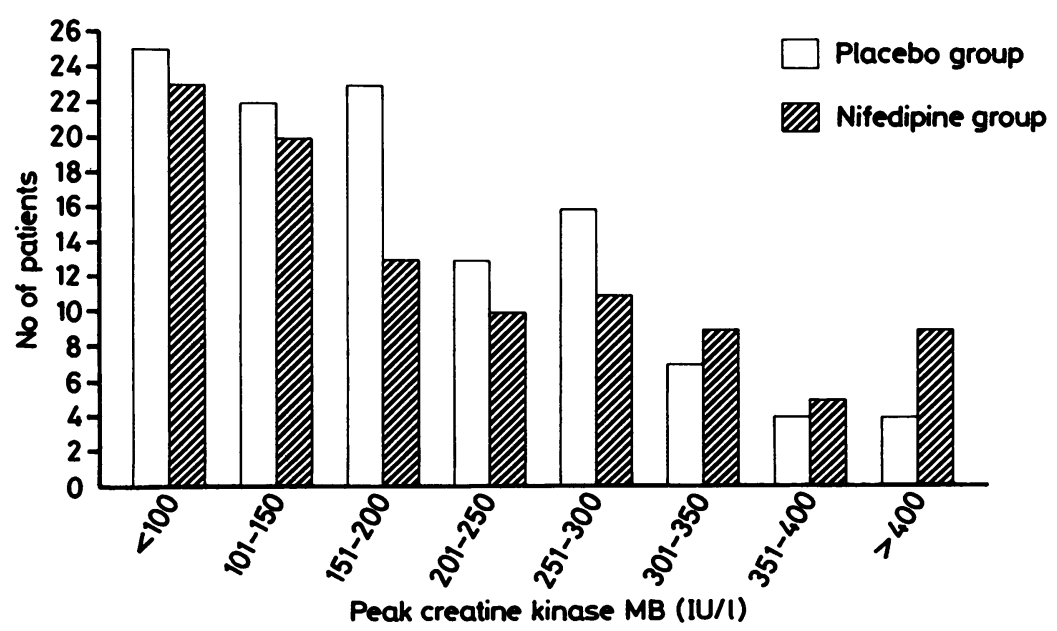

Fig 3 Distribution of the peak creatine kinase $M B$ values in 100 patients with myocardial infarction treated with nifedipine and 114 treated with placebo. 
Table 4 Total creatine kinase (IU/l) released by nifedipine and placebo treated groups

\begin{tabular}{lll}
\hline & $\begin{array}{l}\text { Nifedipine } \\
(n=77) \\
(\text { Mean }(S E M))\end{array}$ & $\left.\begin{array}{l}\text { Placebo } \\
(n=89) \\
(\text { Mean }\end{array}(S E M)\right)$ \\
\hline $\begin{array}{l}\text { Total creatine kinase released } \\
\text { Range of creatine kinase }\end{array}$ & $\begin{array}{l}2749 \cdot 64(165 \cdot 14) \\
591-9623\end{array}$ & $\begin{array}{l}2698 \cdot 39(145 \cdot 86) \\
483-7154\end{array}$ \\
\hline
\end{tabular}

(291) $\left(10^{-7}\right)$ and $7042(277)\left(10^{-7}\right)$ in the placebo group. These values were not significantly different (Student's $t$ test).

ASPARTATE TRANSAMINASE AND MYOGLOBIN Patients were excluded from the analysis if cardioversion had been performed, if cardiogenic shock had developed, or if they had had intramuscular injections, because these factors are known to interfere with measurement of aspartate transaminase and myoglobin.

Peak mean (SEM) aspartate transaminase was $271.34(17.36) \mathrm{IU} / 1$ in the treatment group and 268.51 (16.32) IU/1 in the placebo group. The range of peak aspartate transaminase was 58-840 IU/1 in the treatment group and 39-930 IU/1 in the placebo group. Peak mean (SEM) myoglobin was 1029 $(108.34) \mathrm{IU} / 1$ in the treatment group and 886.36 $(72 \cdot 88) \mathrm{IU} / 1$ in the placebo group. The range of peak myoglobin was 54-7125 IU/1 in the treatment group and 53-4725 IU/1 in the placebo group.

Mean (SEM) time to peak aspartate transaminase was $24.35(0.66)$ hours in the treatment group and $23.79(0.65)$ hours in the placebo group. Time to peak myoglobin was $10.99(0.47)$ hours in the treatment group and $9.63(0.45)$ hours in the placebo group.

Thus none of the measured variables was significantly different in the nifedipine and placebo groups.

The frequency of early ventricular fibrillation during the 48 hour study period, and of pulmonary oedema, reinfarction, and cardiogenic shock during

Table 5 Occurrence of early ventricular fibrillation during the 48 hour study period and in hospital complications with need for special procedures in patients with myocardial infarction

\begin{tabular}{|c|c|c|}
\hline & $\begin{array}{l}\text { Nifedipine } \\
(\%) \\
(n=106)\end{array}$ & $\begin{array}{l}\text { Placebo } \\
(\%) \\
(n=120)\end{array}$ \\
\hline $\begin{array}{l}\text { Early ventricular fibrillation } \\
\text { Pulmonary oedema } \\
\text { Reinfarction } \\
\text { Cardiogenic shock } \\
\text { Cardioversion } \\
\text { Temporary pacemaker } \\
\text { insertion } \\
\text { In hospital mortality }\end{array}$ & $\begin{array}{rr}4 & (3 \cdot 8) \\
12 & (11 \cdot 3) \\
5 & (4 \cdot 7) \\
3 & (2 \cdot 8) \\
10 & (9 \cdot 4) \\
6 & (5 \cdot 7) \\
7 & (6 \cdot 6)\end{array}$ & $\begin{array}{r}9(7.5) \\
16(13.3) \\
3(2.5) \\
1(0.8) \\
12(10.0) \\
2(1.7)\end{array}$ \\
\hline
\end{tabular}

Table 6 Need for additional treatment during the 48 hour study period in patients with myocardial infarction

\begin{tabular}{|c|c|c|}
\hline Additional drug & $\begin{array}{l}\text { Nifedipine } \\
(\%) \\
(n=106)\end{array}$ & $\begin{array}{l}\text { Placebo } \\
(\%) \\
(n=120)\end{array}$ \\
\hline $\begin{array}{l}\text { Metoclopramide } \\
\beta \text { blocker } \\
\text { Diuretic } \\
\text { Digoxin } \\
\text { Lignocaine } \\
\text { Mexiletine } \\
\text { Long acting nitrate } \\
\text { Dobutamine }\end{array}$ & $\begin{array}{r}18(17 \cdot 0) \\
39(36 \cdot 8) \\
48(45 \cdot 3) \\
8(7 \cdot 5) \\
16(15 \cdot 1) \\
9(8 \cdot 5) \\
37(34 \cdot 9) \\
5(4 \cdot 7)\end{array}$ & $\begin{array}{r}21(17 \cdot 5) \\
37(30 \cdot 8) \\
58(48 \cdot 3) \\
8(9 \cdot 7) \\
21(17 \cdot 5) \\
13(10 \cdot 8) \\
53(44 \cdot 2) \\
2(1 \cdot 7)\end{array}$ \\
\hline
\end{tabular}

the hospital stay was not different in the two groups (table 5). The need for special procedures, including cardioversion and insertion of a temporary transvenous pacemaker, was not significantly different in the two groups ( $\chi^{2}$ test) (table 5 ). Seven patients in each group died during the hospital stay (table 5).

The needs of patients for additional drugs (metoclopramide, $\beta$ blockers, diuretics, digoxin, lignocaine or mexiletine, and preparations containing nitrate or dobutamine) in the $\mathbf{4 8}$ hour study period were not significantly different in the two groups (table 6).

\section{SUBGROUP ANALYSIS}

Infarct sizes estimated by total creatine kinase $\mathrm{MB}$ released by different sites and types of myocardial infarction were compared. The number of patients was too small for meaningful analysis, except in patients with transmural myocardial infarction. In these patients, total mean (SEM) creatine kinase MB released was significantly larger $(496.4(32.0) \mathrm{IU} / \mathrm{l})$ in the treatment group $(n=65)$, than in the placebo group $(383 \cdot 9(24 \cdot 4)$ IU/1) $(n=72)$.

\section{Discussion}

The 48 hour treatment regimen of nifedipine used in this study did not affect infarct size as measured by total creatine kinase $\mathrm{MB}$ released or total creatine kinase released. Nor did it have an effect on cruder $\mathcal{N}$ indicators of infarct size, including peak activities of creatine kinase $\mathrm{MB}$, peak creatine kinase, peak aspartate transaminase, and peak myoglobin concentration. These findings confirm the results of similarly designed studies by Muller et $a l^{8}$ and Sirnes et al, ${ }^{9}$ who suspected that the failure of nifedipine to limit $\stackrel{\oplus}{\rightarrow}$ infarct size was related to the relatively late intervention times in their studies (mean delay 4.6 hours and 5.5 hours respectively). This was not a feature of our study (mean total delay time in the treatment group was 2.3 hours). In a study by Branagan et al (1986) mean delay time to intervention with nifedipine was 
3.3 hours but the number of patients in this study in whom infarct size was obtainable was too small for meaningful analysis (23 in the nifedipine treated group and 17 in the placebo group) and there was no difference between the groups reported. ${ }^{13}$ Perhaps the dose and frequency of nifedipine used were suboptimal. But we were reluctant to expose patients to the hazard of excessive vasodilatation which could have resulted with larger doses of nifedipine. The dose of nifedipine chosen had in any case been shown to produce favourable haemodynamic effects in acute myocardial infarction. ${ }^{7}$ This earlier study found that in patients treated with nifedipine cardiac output was significantly higher and peripheral vascular resistance significantly lower than in control patients. Logically this reduction in afterload should reduce myocardial oxygen demand because cardiac work is less and hence infarct size should be reduced.

\section{WHY DOES NIFEDIPINE FAIL TO LIMIT INFARCT SIZE?}

The apparent lack of effect of nifedipine on the limitation of infarct size may be related to the development of relative hypotension in some patients, which would offset any benefit. Such a phenomenon was seen in experimental studies by Selwyn $e t a l^{\beta}$ and Welman et al. ${ }^{2}$ They found that infarct size was increased in subgroups of animals treated with a dose of nifedipine that was 13 times higher than the dose that reduced infarct size. They suggested that this result could have been caused by the relative hypotension and reflex tachycardia produced by the larger dose of nifedipine. There was no evidence to suggest that this occurred in the studies performed by Muller et al ${ }^{8}$ and Sirnes et al. ${ }^{9}$ Similarly, in our study there was nothing to suggest that relative hypotension was a problem - there was no significant difference in the number of patients with cardiogenic shock between the nifedipine treated group and the placebo group (table 5). Perhaps the lack of evidence of a reduction in infarct size was related to the enzymatic method used. None the less, enzymatic estimation of infarct size by release of total creatine kinase $\mathrm{MB}$ has been validated by Grande $e t$ al $^{14}$ and Hackel $e t ~ a l^{15}$ who found a close correlation with anatomical infarct size.

Our finding of a significant increase in infarct size as estimated by total creatine kinase $\mathrm{MB}$ released in patients with transmural infarction in the nifedipine treated group was unexpected and is difficult to explain.

Any intervention study in which enzymatic estimation of infarct size is the major end point requires a large number of patients in the treatment and control groups to allow for the variability of infarct size between patients. It is possible that nifedipine may have decreased infarct size but not to a detectable extent, given the statistical power of our study, which was designed to have a $95 \%$ chance of detecting a $20 \%$ reduction in infarct size as measured by total creatine kinase $M B$ released. Estimation of the numbers required for any intervention study in acute myocardial infarction is complicated by the fact that the scale of reduction necessary to affect prognosis is not known. Like us, most investigators have aimed at discovering whether a 20 or $30 \%$ reduction in infarct size could be obtained. What is known, however, is that in patients with myocardial infarction who have cardiogenic shock there is invariably evidence of extensive myocardial damage. ${ }^{16-18}$

In conclusion, early intervention with nifedipine treatment in the acute phase of myocardial infarction appears to have no effect on infarct size as measured enzymatically by total creatine kinase MB released, total creatine kinase released, nor does it seem to have any impact on peak aspartate transaminase activity or peak myoglobin concentrations. In hospital mortality in treatment and placebo groups was not significantly different. The contrast in the efficacy of nifedipine in the experimental and clinical settings makes us doubt the value of experimental assessment of limitation of infarct size.

\section{References}

1 Henry PD, Shuchleib R, Borda LJ, Roberts R, Williams JR, Sobel BE. Effects of nifedipine on myocardial perfusion and ischemic injury in dogs. Circ Res 1978;43:372-80.

2 Welman E, Carroll BJ, Lawson JS, Selwyn AP, Fox KM. Effects of nifedipine on creatine kinase release during myocardial ischemia in dogs. Eur $J$ Cardiol 1978;7/5-6:379-89.

3 Selwyn AP, Welman E, Fox K, Horlock P, Pratt T, Klein $M$. The effects of nifedipine on acute experimental myocardial ischemia and infarction in dogs. Circ Res 1979;44:16-23.

4 Clark RE, Christlieb IY, Henry PD, et al. Nifedipine: a myocardial protective agent. Am J Cardiol 1979; 44:825-31.

5 Melin JA, Becker LC, Hutchins GM. Protective effect of early and late treatment with nifedipine during myocardial infarction in the conscious dog. Circulation 1984;69:131-41.

6 Yoshida S, Downey JM, Friedman FR, Chambers DE, Hearse DJ, Yellon DM. Nifedipine limits infarct size for 24 hours in closed chest coronary embolized dogs. Basic Res Cardiol 1985;80:76-87.

7 Gordon GD, Mabin TA, Isaacs S, Lloyd EA, Eichler HG, Opie LH. Hemodynamic effects of sublingual nifedipine in acute myocardial infarction. Am J Cardiol 1984;53:1228-32.

8 Muller JE, Morrison J, Stone PH, et al. Nifedipine therapy for patients with threatened and acute 
myocardial infarction: a randomized, double-blind, placebo-controlled comparison. Circulation 1984;69:740-7.

9 Sirnes PA, Overskeid K, Pedersen TR, et al. Evolution of infarct size during the early use of nifedipine in patients with acute myocardial infarction: The Norwegian Nifedipine Multicenter Trial. Circulation 1984;70:638-44.

10 Wilcox RG, Hampton JR, Banks DC, et al. Trial of early nifedipine in acute myocardial infarction: the Trent study. Br Med J 1986;293:1204-8.

11 Blanke $\mathrm{H}$, von Hardenberg $\mathrm{D}$, Cohen $\mathrm{M}$, et al. Patterns of creatine kinase release during acute myocardial infarction after nonsurgical reperfusion: comparison with conventional treatment and correlation with infarct size. J Am Coll Cardiol 1984;3:675-80.

12 Norris RM, Whitlock RML, Barratt-Boyes C, Small CW. Clinical measurement of myocardial infarct size. Modification of a method for the estimation of total creatine phosphokinase release after myocardial infarction. Circulation 1975;51:614-20.

13 Branagan JP, Walsh K, Kelly P, Collins WC,
McCafferty D, Walsh MJ. Effect of early treatment with nifedipine in suspected acute myocardial infarction. Eur Heart $J$ 1986;7:859-65.

14 Grande P, Hansen BF, Christiansen C, Naestoft J. Acute myocardial infarct size estimated by serum CK-MB determinations: clinical accuracy and prognostic relevance utilizing a practical modification of the isoenzyme approach. Am Heart $J 1981 ; 101$ :582-6.

15 Hackel DB, Reimer KA, Ideker RE, et al. Comparison

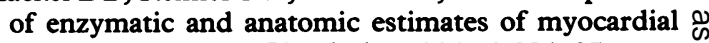
infarct size in man. Circulation 1984;70:824-35.

16 Harnarayan C, Bennett MA, Pentecost BL, Brewer DB. Quantitative study of infarcted myocardium in cardiogenic shock. Br Heart J 1970;32:728-32.

17 Page DL, Caulfield JB, Kastor JA, DeSanctis RW, Sanders CA. Myocardial changes associated with cardiogenic shock. $N$ Engl J Med 1971;285:133-7.

18 Alonso DR, Scheidt S, Post M, Killip T. Pathophysiology of cardiogenic shock. Quantification of myocardial necrosis, clinical, pathologic and electrocardiographic correlations. Circulation 1973;48: 588-96. 